\title{
Ilhas Interdisciplinares de Racionalidade: conceito de proporcionalidade na compreensão de informações contidas em rótulos alimentícios
}

Josiane Bernz Siqueira

Rosinéte Gaertner

\begin{abstract}
Resumo
As Ilhas Interdisciplinares de Racionalidade - IIR é uma metodologia de ensino voltada para a Alfabetização Científica e Tecnológica proposta por Gérard Fourez, que visa à formação de estudantes críticos, autônomos e que saibam negociar perante situações que demandam atuação incisiva na sociedade. Neste artigo apresentamos parte de uma pesquisa que teve como objetivo geral analisar as contribuições da metodologia para a aprendizagem do conceito de proporcionalidade explorando rótulos alimentícios. Os sujeitos da pesquisa do tipo qualitativa participante foram 23 estudantes matriculados em uma turma do 8 o ano. No desenvolvimento do trabalho foram organizadas e aplicadas as oito etapas que compõem a metodologia IIR. Os resultados evidenciaram que o ensino quando apresentado de forma contextualizada e articulada de maneira interdisciplinar provoca nos estudantes a vontade de construir seu próprio conhecimento de modo mais sofisticado, promovendo a Alfabetização Científica.
\end{abstract}

Palavras-chave: ensino de matemática, alfabetização científica, interdisciplinaridade, proporção.

\section{Abstract \\ Islands of Interdisciplinary Rationality: proportionality concept in understanding of information contained in food labels}

The Interdisciplinary Islands Rationality - IIR is a teaching methodology focused on Scientific and Technological Literacy proposed by Gérard Fourez, which aims at training students critical, autonomous and know negotiate in situations that require incisive role in society. This article presents a study that aimed to analyze the contributions of the methodology for learning the concept of proportionality exploring food labels. The research subjects participant qualitative study were 23 students enrolled in a class in the 8th grade. In developing this work were organized and implemented the eight races that make up the IIR methodology. The results showed that teaching as presented in context and articulated form of interdisciplinary way causes in students the desire to build your own more sophisticated way of knowledge, promoting Scientific Literacy. proportion.

Keywords: mathematics teaching, scientific literacy, interdisciplinary, 


\section{Introdução}

As Ilhas Interdisciplinares de Racionalidade - IIR é uma metodologia de ensino proposta por Gérard Fourez, diante da perspectiva de Alfabetização Científica e Tecnológica - ACT. O autor acredita que tal metodologia favorece o desenvolvimento da autonomia dos estudantes e afirma que: "Uma pessoa que é capaz de representar situações específicas, poderá tomar decisões razoáveis e racionais contra uma série de situações problemas". (FOUREZ, 1997, p. 61) Ele determina três características para que um estudante seja considerado Alfabetizado Cientificamente, que possua "autonomia (possibilidade de negociar suas decisões perante as pressões naturais e sociais), uma certa capacidade de comunicar (encontrar maneiras de dizer), um relativo domínio e responsabilidade, frente a uma situação concreta" (FOUREZ, 1997, p. 62, grifo do autor).

Para desenvolver a metodologia Ilhas Interdisciplinares de Racionalidade em sala de aula utilizamos como contexto os rótulos de embalagens alimentícias, com o intuito de abordar o conteúdo conceitual de proporcionalidade. Os rótulos de alimentos configuram-se como principal meio de comunicação entre consumidores e produtos. É importante que os consumidores saibam interpretar e compreender as informações contidas nos rótulos para orientar a escolha do alimento mais adequado à sua saúde. A Agência Nacional de Vigilância Sanitária afirma que 70\% das pessoas consultam os rótulos no momento da compra, no entanto, mais da metade não compreende adequadamente o significado das informações.

Diante de tal situação, podemos nos perguntar de que forma a escola pode contribuir para auxiliar a melhorar este índice e, consequentemente, para a formação do cidadão. Para a compreensão mínima de uma rotulagem alimentícia são necessários saberes preconizados nos Parâmetros Curriculares Nacionais- PCN, dentre os quais podemos citar, referentes à disciplina de matemática, os conteúdos: grandezas e medidas, razão e proporção. Além disso, os Parâmetros também atentam para a importância da contextualização no que tange ao consumismo:

"Aspectos ligados aos direitos do consumidor também necessitam da Matemática para serem mais bem compreendidos. Por exemplo, para analisar a composição e a qualidade dos produtos e avaliar seu impacto sobre a saúde e o meio ambiente, ou para analisar a razão entre menor preço/maior quantidade. Nesse caso, situações de oferta como "compre 3 e pague 2" nem sempre são vantajosas, pois geralmente são feitas para produtos que não estão com muita saída - portanto, não há, muitas vezes, necessidade de comprá-los em grande quantidade - ou que estão com os prazos de validade próximos do vencimento. Habituar-se a analisar essas situações é fundamental para que os alunos possam reconhecer e criar formas de proteção contra a propaganda enganosa e contra os estratagemas de marketing a que são submetidos os potenciais consumidores." (BRASIL, 1998a, p. 35)

R. B. E. C. T., vol 8, Ed. Sinect, jan-abr.2015 ISSN - 1982-873X

DOI: Em andamento. 
Então, se um estudante é capaz de "analisar a composição e a qualidade dos produtos e avaliar seu impacto sobre a saúde e o meio ambiente, ou [...] analisar a razão entre menor preço/maior quantidade" (BRASIL, 1998a, p. 35) possivelmente isto seria um dos indicadores de que ele está no processo da Alfabetização Científica.

O objetivo deste trabalho é analisar as contribuições da metodologia proposta por Fourez, Ilhas Interdisciplinares de Racionalidade na aprendizagem do conceito de proporcionalidade. Foram 23 estudantes que participaram do projeto interdisciplinar, matriculados em uma turma do 8 o ano de uma escola pública da rede municipal de Gaspar - SC. Neste contexto apresentamos nossa questão da pesquisa:

Quais as contribuições da metodologia proposta por Fourez, Ilhas Interdisciplinares de Racionalidade, para a aprendizagem do conceito de proporcionalidade?

Assim, germina a ideia de desenvolver um projeto interdisciplinar, sobre a compreensão de informações contidas em rótulos alimentícios, a fim de promover o pensamento proporcional, a criticidade econômica e o consumismo saudável dos estudantes e seus familiares.

\section{Ilhas Interdisciplinares de Racionalidade}

Quando almejamos por estudantes autônomos, críticos e atuantes na sociedade, estamos também almejando que nossa prática promova a Alfabetização Científica - AC. Desta forma, quando o interesse pela $A C$ surge, vêm com ele diversos questionamentos e o principal é: como ensinar essas competências tão amplas? Autonomia, comunicação com os outros e domínio são questões ensináveis? Para Fourez a Alfabetização Científica se desenvolve acerca de objetivos humanísticos, sociais e econômicos. Os objetivos humanísticos requerem capacidades de se situar em um mundo técnico-científico, e poder usufruir destes conhecimentos para fazer a leitura do mundo atual. Os objetivos sociais demandam a diminuição das desigualdades, gerando assim, a autonomia e a criticidade diante de fatores sociais entre os indivíduos de uma mesma sociedade. Os objetivos econômicos e políticos estão ligados à participação efetiva do cidadão no desenvolvimento do potencial tecnológico e econômico do mundo. (FOUREZ, 2003, p. 113)

Tais objetivos também se destacam nas características da disciplina de matemática descritas pelos Parâmetros Curriculares Nacionais (1998a, p. 24) no qual aponta que a disciplina “[...] caracteriza-se como uma forma de compreender e atuar no mundo e o conhecimento gerado nessa área do saber como um fruto da construção humana na sua interação constante com o contexto natural, social e cultural." Além disso, o PCN (1998a, p. 26) de matemática destaca que:

"A sobrevivência na sociedade depende cada vez mais de conhecimento, pois diante da complexidade da organização social, a falta de recursos para obter e

162 DOI: Em andamento.

R. Bras. de Ensino de C\&T 
interpretar informações, impede a participação efetiva e a tomada de decisões em relação aos problemas sociais."

Semelhante ao PCN, a proposta da Alfabetização Científica e Tecnológica advém da necessidade de desenvolver relações mais profundas entre saberes escolares, ciência e tecnologia. Lucchesi (2010, p. 29) afirma que o objetivo da ACT é capacitar o estudante de modo que utilize os saberes científicos na prática da vida cotidiana. E que isto aconteça por meio de um ensino que contemple questionamentos, reflexões e a participação em decisões.

Para que um estudante seja considerado alfabetizado científico-tecnicamente, Fourez (1997, p. 61) determina três características: autonomia (componente humanístico), comunicação (componente social) e domínio e responsabilidade (componente econômico). Betaninn (2003, p. 30) destaca que estas três características perpassam pela negociação, que está relacionada diretamente com o conhecimento. "[...] é a partir dele que o indivíduo passa a entender melhor as situações naturais e/ou sociais que o cercam, e isso facilitará a tomada de decisões frente a tais situações."

Neste sentido, Fourez propõe uma metodologia de ensino denominada Ilhas Interdisciplinares de Racionalidade, o qual caracteriza uma modelização, ou representação teórica de uma situação particular. "Trata-se de inventar, frente a um projeto, um modelo adequado, suficientemente simples, utilizando conhecimentos provenientes de diversas disciplinas - e também saberes da vida cotidiana - indispensáveis em situações concretas" (FOUREZ, 1997, p. 69 , grifo do autor, tradução nossa).

A Ilha Interdisciplinar de Racionalidade é uma metodologia ou um meio para direcionar o trabalho que será feito. "Assim, a definição sobre o que será feito na atividade não é determinada pelas diversas disciplinas vinculadas ao tema, mas pelo projeto, por sua finalidade e por seu contexto." (PIETROCOLA et al, 2000, p. 107)

O projeto parte de uma situação problema, o qual irá provocar outros questionamentos mais precisos acerca do contexto estudado, convocando assim saberes de disciplinas diferentes. Bettanin (2003, p. 36 - 37) esclarece que "A construção de uma llha parte de uma situaçãoproblema que envolve aspectos do cotidiano do aluno e tem como objetivo dar significado ao ensino escolar" e afirma que a metodologia "[...] envolve um contexto e um projeto que ultrapassa os domínios disciplinares e que direciona a uma conclusão com elaboração de um produto final.".

Neste contexto, Fourez propõe uma sequência de etapas que viabilizam a construção de uma Ilha Interdisciplinar de Racionalidade promovendo assim, a Alfabetização Científica e Técnica. São oito as etapas propostas por Fourez, no entanto, o autor afirma que no percurso do projeto não há a necessidade de se cumprir todas de forma linear "elas são flexíveis e abertas, em 
alguns casos podendo ser suprimidas e/ou revisitadas, quantas vezes a equipe julgar necessário." (PIETROCOLA et al, 2000, p. 108). A seguir, apresentamos cada etapa.

Etapa 1 - Elaboração de um Clichê da situação estudada: O clichê é um conjunto de questionamentos de um grupo, que exprimem suas concepções e dúvidas acerca de um contexto. Representa o ponto de partida da atividade. "Para isto, a equipe se interrogará, em um brainstorming, indo de questões mais gerais até as mais precisas" (FOUREZ, 1997, p. 113, grifo do autor, tradução nossa). Tais questionamentos podem conceber pensamentos corretos ou errados a respeito da situação estudada, já que este é o primeiro contato oficial perante o projeto. No entanto, não devemos fazer julgamentos precipitados, pois as dúvidas e as concepções do grupo partem da experiência cotidiana e ocorrem espontaneamente. Portanto, podem estar carregadas de preconceitos, crendices e superstições.

O resultado desta etapa poderá ser uma lista de questionamentos e concepções, ou ainda, um esquema desses primeiros pensamentos a respeito do assunto estudado. Maingain e Dufour (2008, p. 92) afirmam que o importante é "antes de explorar uma problemática interdisciplinar, verificar o campo de conhecimento dos alunos e assegurar-se da existência de uma bagagem suficiente para fazer arrancar o processo."

Etapa 2 - Elaboração de um Panorama Espontâneo: Nesta etapa é ampliado o contexto do clichê, ainda assim dentro de uma situação espontânea por não articular-se com especialistas e especialidades no assunto. Pinheiro e Pinho Alves $(2005$, p. 2) destacam que:

"Nela ocorrem várias ações, tais como o refinamento das questões, a definição dos participantes, o levantamento de normas e restrições de interesses e tensões, listagem dos diversos aspectos da situação que serão abordados, escolha dos caminhos a seguir, listagem das especialidades e dos especialistas envolvidos com a situação."

Todas essas ações ajudam na orientação das escolhas diante do que se quer do projeto. Estas listagens auxiliam na promoção dos objetivos da metodologia.

Etapa 3 - Consulta aos Especialistas e às Especialidades: É o estágio em que o grupo define quais especialistas irão consultar. Um especialista é uma pessoa que possui um conhecimento específico de uma determinada situação. Podendo ser um professor ou uma pessoa de outra área com formação acadêmica ou não, como: engenheiros, médicos, administradores, costureiras, atendentes de loja, padeiros, etc.

Esta etapa está vinculada à abertura de caixas pretas, ou seja, conceitos ainda desconhecidos pelos estudantes. Por isso é importante a seleção e a negociação dos questionamentos que deverão ser aprofundados. No caso, um especialista pode ajudar a entender com mais detalhes alguma situação. Neste sentido Fourez (1997, p. 64) esclarece que o bom uso de um especialista faz parte de uma das características de estar alfabetizado científico- 
tecnicamente, como: saber se comportar diante de um especialista, saber quando é sensato desconsiderar a sua opinião, saber se é necessário buscar uma segunda opinião, saber como transferir o conhecimento do especialista de um contexto ao outro, saber adaptar nossos saberes com as competências mais abstratas do especialista. Assim, Schmitz (2004, p. 109) aponta três tipos de critérios para a escolha de um especialista: "A Situação-Problema, o produto selecionado e os especialistas disponíveis."

Lembramos que a participação de especialistas faz parte da construção de uma llha Interdisciplinar de Racionalidade, e a forma que a equipe irá conduzi-la fará com que o projeto realmente tenha a característica de ser interdisciplinar, não ficando apenas na superficialidade da situação.

Etapa 4 - Ir à Prática: É a fase mais aproximada do cotidiano, no qual pode haver: entrevistas, saídas de estudo, pesquisas, leituras, desmontar uma ferramenta tecnológica, entre outras práticas. Este é o momento em que saímos do abstrato e trabalhamos com o concreto.

Fourez (1997, p. 117) utiliza o termo "Descer ao terreno" partindo da conjectura do que conhecemos, para então aprimorá-la. "O objetivo desta etapa é de ter uma noção mais concreta da situação" (FOUREZ apud SCHMITZ, 2004, p.113). E registra que ir à prática depende dos objetivos do projeto e dos atores envolvidos na construção de uma llha de Racionalidade. Podemos dizer que esta fase representa ao estudante o momento pelo qual ocorre a maior aproximação entre o contexto estudado e o cotidiano.

Etapa 5 - Abertura aprofundada de alguma Caixa Preta para buscar Princípios Disciplinares: Esta etapa consiste no aprofundamento de conteúdos conceituais que perfazem disciplinas específicas. Fourez (1997, p. 118, tradução nossa) afirma que "Nesta fase pode-se, na forma de uma investigação mais fundamental, aprofundar um ou outro aspecto do contexto estudado, com o rigor de uma disciplina científica." E acrescenta que cada conteúdo é escolhido em função do contexto do projeto e dos estudantes.

Etapa 6 - Esquematizando a situação pensada: É a fase de compor uma síntese parcial ou um esquema que relate o que foi estudado a partir da Ilha Interdisciplinar de Racionalidade. Esta etapa caracteriza-se pela apresentação do que já foi trabalhado durante o percurso do projeto e apresenta resultados parciais da pesquisa. A síntese da IIR pode ser apresentada através de um desenho, mapa conceitual, vídeo, maquete, texto, resumo, enfim, algo que representa o que já foi conquistado.

Etapa 7 - Abrir algumas Caixas Pretas sem a ajuda de um Especialista: Nesta fase o grupo poderá aprofundar questionamentos, ou caixas pretas, sem a ajuda de um especialista. Esta etapa caracteriza-se como um complemento das etapas anteriores, haja vista que poderá ocorrer a necessidade de buscar alguém que não esteja disponível. Neste caso, fica a responsabilidade de buscar as informações necessárias, à própria equipe. “Desta maneira eles constroem modelos 
aproximados e provisórios, que mesmo não contendo todo o rigor necessário, tratam de situações envolvendo o cotidiano e produzindo um sentimento de autonomia neles." (SCHMITZ, 2004, p. 115)

Muitos recursos poderão ser utilizados para desencadear esta etapa, como: internet, livros, revistas, vídeos, entre outros materiais.

Etapa 8 - Síntese da Ilha Interdisciplinar de Racionalidade (Produto final): Consiste na elaboração de um texto, relato ou síntese do que foi construído durante o processo, tomando o cuidado de não abranger somente uma disciplina. Maigain e Dufour (2008, p. 100, grifo dos autores) completam que esta "... última etapa consiste, com efeito, em testar a representação construída.". Tal etapa pode ser concretizada através de vários modelos desde que seja construído de forma que retrate o que foi aprendido durante o percurso.

A metodologia IIR está implicitamente ligada à promoção da Alfabetização Científica e Técnica, a qual objetiva a formação de estudantes autônomos, que dominem o diálogo e utilizem seu conhecimento com responsabilidade. E, caracteriza-se como uma alternativa para promover a ACT dentro das escolas. Utilizar a metodologia IIR nas escolas possibilita aos professores realizar o acompanhamento de um projeto de forma sistêmica, com coerência nas aberturas de caixas pretas.

\section{Rótulos alimentícios e o conceito de proporcionalidade}

Os rótulos configuram-se como o principal meio de comunicação entre consumidor e produto. Portanto, é imprescindível que os consumidores saibam interpretar e compreender as informações contidas nos rótulos a fim de orientar a escolha do alimento mais adequado à sua saúde.

O estudo das informações em rótulos alimentícios é citado nos Temas Transversais, dentro do eixo: Trabalho e Consumo. $O$ documento sugere algumas intervenções didáticas que podem ser feitas de acordo com o tema como: o uso de aditivos em alimentos, composição do produto, relação quantidade e preço - qualidade e preço, embalagem e meio ambiente, comparação entre um mesmo produto de marcas diferentes, orçamentos, visualização e clareza da data de validade, peso bruto e peso líquido e por fim a influência da mídia com propagandas enganosas (BRASIL, 1998b). Além disso, os Temas Transversais possuem a característica de envolver questões sociais.

"Tratam de processos que estão sendo intensamente vividos pela sociedade, pelas comunidades, pelas famílias, pelos alunos e educadores em seu cotidiano. São debatidos em diferentes espaços sociais, em busca de soluções e de alternativas [...] Por outro lado, sua complexidade faz com que nenhuma 
das áreas, isoladamente, seja suficiente para explicá-los; ao contrário, a problemática dos temas transversais atravessa os diferentes campos do conhecimento." (BRASIL, 1998b, p. 26)

Assim, são necessárias competências e habilidades interdisciplinares para que um consumidor consiga efetuar uma compra, sendo conhecedor de todos os benefícios e malefícios que o alimento poderá proporcionar. Podemos destacar alguns conhecimentos disciplinares diante de uma possível análise de um rótulo alimentício, como: alimentos (nutrientes e funções), digestão (sistema digestório e processos), cores, pesos e medidas, porcentagem e proporcionalidade. Destas, a que iremos dar uma maior ênfase é a última. A proporcionalidade aparece em diferentes análises no rótulo, por exemplo:

$\checkmark$ Comparação de preços entre o mesmo produto, mas de marcas diferentes.

$\checkmark$ Relação quantidade e preço.

$\checkmark$ Situações de oferta como: leve 3 e pague 2 .

$\checkmark$ Cálculos dos valores nutricionais da embalagem inteira em relação à porção apresentada na tabela nutricional.

$\checkmark$ Relação entre os valores diários de referência para cada nutriente e o valor nutricional do produto inteiro.

A proporção é um conteúdo curricular matemático que permeia por vários outros. Tinoco (2011, p. 10) o menciona como "conteúdo integrador dos diversos ramos da matemática", pois é facilmente relacionado com outros conteúdos e outras disciplinas. "São inúmeras as aplicações desse conceito à geografia, à física, à química, etc."

O PCN de Matemática (1998a, p. 65) aponta como objetivos para o estudo do raciocínio proporcional, situações de aprendizagem que levem o estudante a: "observar a variação entre grandezas, estabelecendo relação entre elas e construir estratégias de solução para resolver situações que envolvam a proporcionalidade." Oliveira (2014, p. 53) diz que o raciocínio proporcional requer capacidades de "interpretar, fazer predições, elaborar hipóteses, justificar ideias, elaborar e apresentar argumentos que justifiquem a escolha e aplicação de estratégias/procedimentos para resolução de problemas". Além disso, menciona que o raciocínio "exige conhecimentos variados que devem ser selecionados, organizados e relacionados entre si de maneira coerente."

Salientamos a importância do ensino de proporcionalidade, não somente como um tópico dentro do currículo escolar, mas de tal modo que esse conceito permeie por diversos conteúdos matemáticos e por diferentes disciplinas. Assim, seu ensino poderá ser mais significativo para o estudante. Vale lembrar que a formalização dos conceitos e o ensino do algoritmo da regra de três são peças importantes na constituição do raciocínio proporcional. No entanto, podemos 
iniciar com problemas peculiares ao cotidiano dos estudantes, para que eles se sintam seguros na elaboração de estratégias de resolução e que façam sentido na vida escolar dos mesmos.

\section{Metodologia}

A metodologia da pesquisa adotada para desenvolver o trabalho é a do tipo qualitativa participante, no qual pesquisador e professor são os mesmos sujeitos. $\mathrm{O}$ trabalho foi desenvolvido em uma escola da rede municipal de Gaspar (Santa Catarina). A turma que participou da atividade foi a do 8 o ano do período matutino, composta por 23 estudantes, sendo 13 meninos e 10 meninas, com faixa etária entre 12 e 15 anos.

A instituição de ensino, além de se preocupar com o conhecimento científico adquirido pelos estudantes, também apoia e dá suporte aos professores que desejam desenvolver projetos interdisciplinares que enaltecem a responsabilidade, a criticidade, os valores éticos e a cultura local. Assim, os professores de matemática, ciências, artes e filosofia se envolveram diretamente e fizeram parte do trabalho interdisciplinar desenvolvido na escola.

As etapas do projeto foram planejadas pensando no objetivo geral da pesquisa, ou seja: analisar as contribuições da metodologia proposta por Fourez, Ilhas Interdisciplinares de Racionalidade na aprendizagem do conceito de proporcionalidade. Assim, cada etapa foi vista em sua magnitude diante da metodologia investigada. Além disso, planejamos as etapas de modo que pudéssemos analisar a aprendizagem dos estudantes frente ao conceito de proporcionalidade, paralelamente a aplicação das etapas da metodologia IIR.

Neste sentido, pensamos em três critérios para compreender e acompanhar o processo de aprendizagem dos estudantes, já apontados por Fourez:

1. Autonomia para interpretar rótulos de alimentos e assim realizar escolhas mais saudáveis.

2. Comunicação entre estudante $\mathrm{X}$ estudante, estudante $\mathrm{X}$ professores e estudante $\mathrm{X}$ especialistas.

3. Domínio de conteúdos conceituais na análise de rótulos alimentícios.

Para coletar os dados da pesquisa utilizamos como instrumentos os registros no diário de bordo da pesquisadora, registros fotográficos das etapas, gravações em áudio com especialistas, exame dos cadernos dos estudantes. Além disso, também acompanhamos e analisamos as produções individuais e/ou grupos elaborados pelos estudantes, os quais se constituíram em uma importante fonte de dados.

168 DOI: Em andamento. 


\section{Descrição das etapas e análise}

Iniciamos o projeto interdisciplinar com uma dinâmica intitulada "Degustação às Cegas" para inserir os estudantes no contexto dos rótulos alimentícios e chamar a atenção para o conteúdo conceitual de proporcionalidade. O objetivo da dinâmica era descobrir o sabor do suco pelo paladar e identificar a preparação: forte, fraco ou ideal (padrão - como indicado no rótulo). Os estudantes tiveram seus olhos vendados para não ver a coloração do suco, pois este evidenciava o sabor e de algum modo o tipo de preparo do suco. A figura 1 apresenta um estudante degustando o suco para adivinhar o sabor e o preparo.

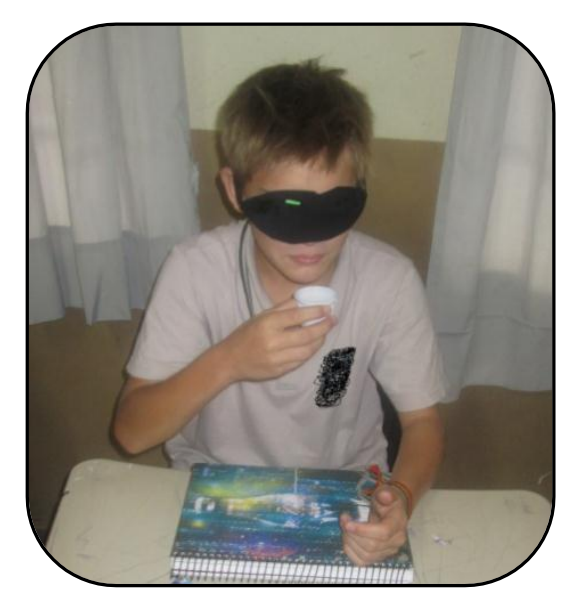

Figura 1 - Estudante degustando o suco para adivinhar o sabor e o preparo.

(Fonte: acervo pessoal da pesquisadora)

Na sequência, apresentamos a descrição das etapas da IIR e a análise.

Etapa 1 - Elaboração de um clichê da situação estudada: Para esta etapa organizamos uma sala, previamente, com mesas contendo rótulos de alimentos diversos.

Os estudantes manusearam os rótulos e identificaram informações que não compreendiam. Cada estudante recebeu uma folha para anotar as dúvidas e questionamentos. Durante a atividade evidenciamos concepções corretas e erradas a respeito de algumas informações contidas nos rótulos. Como mencionado anteriormente, Fourez afirma que esta situação é totalmente compreensível, de modo que estamos numa fase de verificação dos conhecimentos espontâneos. Esta situação é evidenciada na conversa entre os estudantes $E_{1}$ e $E_{2}$ em uma análise de um rótulo de margarina. $\mathrm{E}_{1}$ : "Ômega 3 é para os ossos! Eu vi na TV" $\mathrm{E}_{2}$ : Não, eu vi na TV que é para o coração!" No momento da conversa, os dois estudantes ficaram em dúvida e cada um realizou a sua anotação, da forma que compreendia. 
Etapa 2 - Elaboração de um panorama espontâneo: Esta etapa foi organizada em conjunto pelos professores e estudantes. Selecionamos as dúvidas mais pertinentes registradas no clichê e categorizamos disciplinas e especialistas que poderiam ajudar a responder tais questionamentos. As disciplinas evocadas para auxiliar no desenvolvimento do projeto foram: ciências, artes e matemática. Além disso, elencamos a participação de especialistas na área de: engenharia química, nutrição e marketing. Fourez $(1997$, p. 113) esclarece que esta etapa é uma expansão do clichê e ocorre ainda de maneira bastante espontânea, pois não há a participação de especialistas. Feita a lista de pessoas envolvidas, conversamos com a coordenação para viabilizar a presença dos especialistas na escola, no qual fomos atendidos prontamente.

Etapa 3 - Consulta aos especialistas: Tivemos palestras com engenheiro químico, nutricionista e professor de marketing. Estas palestras ocorreram em momentos diferentes do projeto. Todos os três especialistas partiram das caixas pretas, ou seja, as dúvidas dos estudantes registradas na etapa 1 . Fourez $(1997$, p. 117) chama a atenção para não perder o foco nesta etapa, pois os especialistas possuem muito conhecimento. A seguir, apresentamos os questionamentos encaminhados aos especialistas de acordo com as listas elaboradas na etapa 2.

Questionamentos encaminhados ao especialista da área de engenharia química: a) Porque o chocolate branco é mais calórico que o chocolate preto? b) O que significa "arroz parboilizado"? E o que significa "Tipo 1"? c) Qual a diferença entre óleo de canola e óleo de girassol? d) O que significa a informação "não contém quantidades significativas"? e) Como é colocado gás nos refrigerantes? f) Por que existe sódio em alimentos doces? g) Por que depois de aberto o lorgute só dura 7 dias?

Questionamentos encaminhados ao especialista da área de marketing: a) Por que alguns produtos utilizam personagens de desenho animado?b) Por que tem embalagens que chamam tanto a nossa atenção? c) Por que muitos alimentos possuem "Nova embalagem"?

Questionamentos encaminhados ao especialista da área de nutrição: a) Leite faz mal à saúde? b) Margarina faz bem à saúde? c) Por que os alimentos que achamos saudáveis nunca são, e tem muita gordura? Ex: "Salgadinho B" fonte de energia, fonte de proteína e ácido fólico? c) Por que os leites não podem ser ingeridos por crianças com menos de 1 ano? d) O que significa "Fonte de vitaminas e minerais"? e) Por que água de coco é bom para o corpo humano? f) Por que a tabela nutricional do café está quase toda zerada? g) Ômega 3 faz bem para os ossos ou para o coração?

Nas três palestras, os estudantes foram intensamente participativos, as dúvidas foram esclarecidas, muitas delas eram carregadas de crenças por influência da família. Podemos identificar esta influência na fala entre o estudante $\mathrm{E}_{3}$ e a engenheira química. $\mathrm{E}_{3}$; " $\mathrm{A}$ minha mãe usa óleo de girassol para fritar o bife, ela disse que é mais saudável." Engenheira química: "Realmente, é mais saudável. Mas, quando usamos óleos para fritar e aquecemos, todos eles 
perdem a sua qualidade nutricional e ficam iguais [...] Então, você pode dizer para sua mãe que, se é pra fritar ela pode usar o óleo de soja que é mais barato e tem a mesma função. Agora, se ela vai utilizar o óleo sem aquecer daí o de girassol é mais saudável."

Fourez (1997, p. 117) aponta para a importância do confronto das informações de um especialista em relação aos conhecimentos espontâneos dos estudantes (etapa 1), e a possível visão que pode ser alterada. Na figura 2, apresentamos um esquema com os conteúdos que foram abordados pelos especialistas.

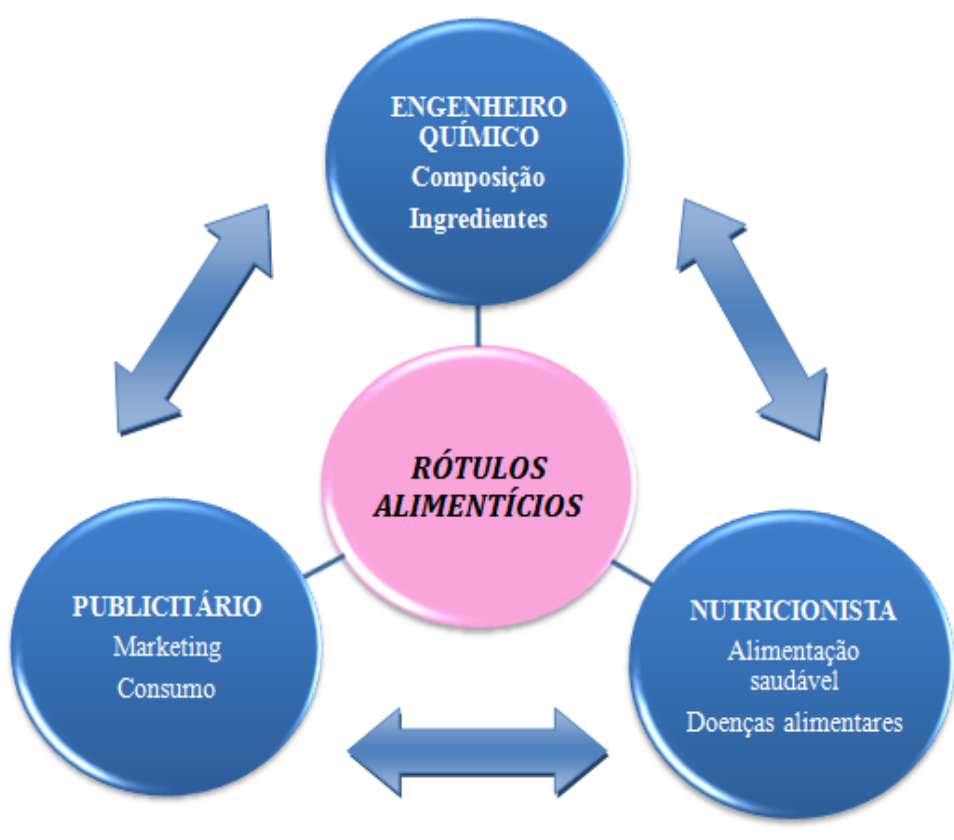

Figura 2 - Esquema de Especialistas e assuntos relacionados a Rótulos Alimentícios.

(Fonte: organizado pela pesquisadora)

Etapa 4 - Ida à prática: Visitamos uma fábrica de conserva de palmito e conhecemos desde a produção até a rotuladeira. Podemos dizer que para os estudantes este foi o momento mais divertido. No entanto, esta etapa deu forças ao projeto e o tornou mais interessante aos olhos deles. Na prática, eles viram todo o processo que um produto, no caso o palmito, passa até chegar a etapa final que é a embalagem com o rótulo. Schmitz (2004, p. 112) afirma que "Abandonamos assim o caráter teórico, ligado à situação, para confrontá-lo mais diretamente com a prática."

Na empresa, fomos guiados por um senhor que conhecia todas as fases de produção do palmito, ele explicou cada uma aos estudantes. Esclareceu ainda que foi uma engenheira química que organizou a tabela nutricional constante no rótulo e que foi uma empresa de publicidade que elaborou o desenho e as demais informações do rótulo. 
Etapa 5 - Abertura aprofundada de alguma caixa preta para buscar princípios disciplinares: Estudamos conteúdos conceituais de matemática, ciências, artes e filosofia. $\mathrm{Na}$ figura 3, apresentamos um esquema dos conteúdos que foram trabalhados a partir dos registros dos estudantes.

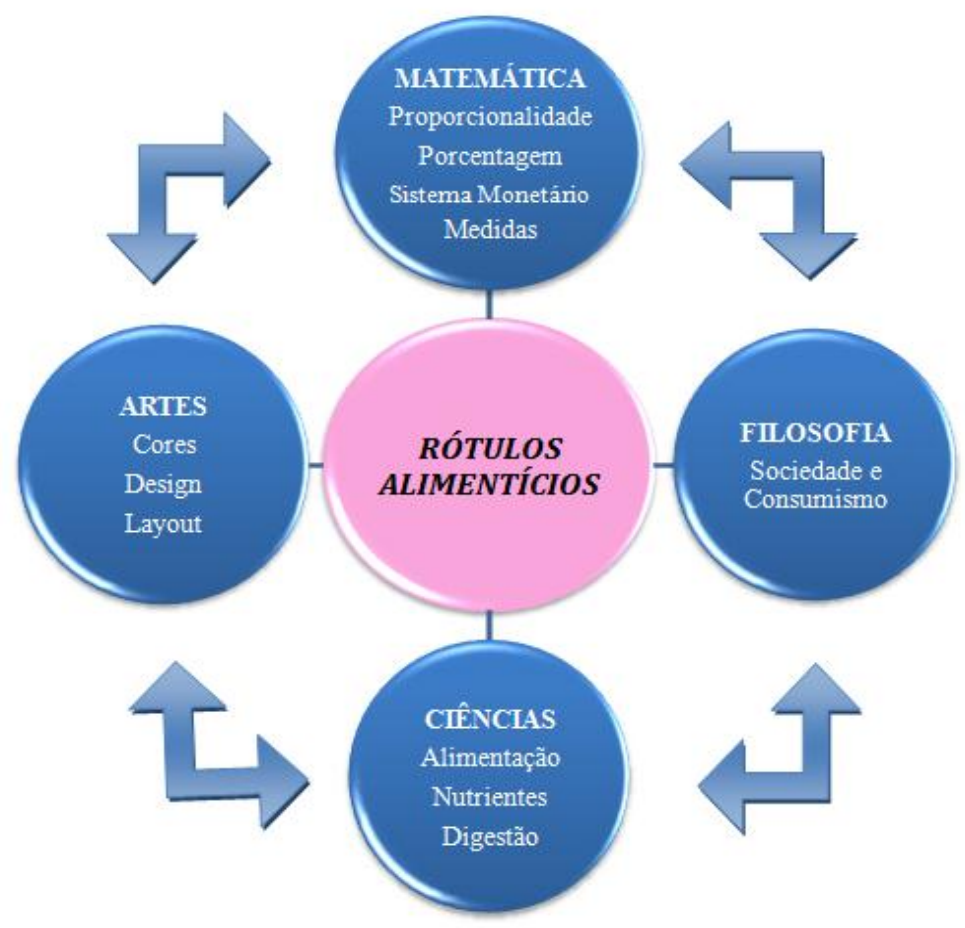

Figura 3 - Esquema das disciplinas e conteúdos

relacionados a Rótulos Alimentícios.

(Fonte: organizado pela pesquisadora)

Destes, vamos pontuar apenas os conteúdos de matemática relacionados à proporcionalidade, que foram estudados: porcentagens na tabela nutricional, comparação de tabelas para verificar se o produto é light ou não, como elaborar uma tabela nutricional, qual o produto mais vantajoso em relação ao preço e peso. Com isso, houve a necessidade de compreender conceitos de grandezas, proporcionalidade, razão e proporção. Também foi necessário estudar sobre a propriedade fundamental das proporções e a regra de três. Maigain e Dufour (2008, p. 98) esclarecem que:

"Na fase da abertura das caixas negras, o professor intervém principalmente enquanto especialista de uma (ou várias) disciplina(s) particular(es), de que ele domina os saberes declarativos, processuais e condicionais. $O$ seu papel mais específico consiste em orientar o aluno na mobilização de conhecimentos e de competências disciplinares, com vista a realizar o projecto." 
Etapa 6 - Esquematizando a situação pensada: Nesta etapa construímos uma tabela nutricional para um bolo de chocolate. Os nutrientes que deveriam constar na tabela foram discutidos nas aulas de ciências, o slogan foi desenvolvido nas aulas de artes e a tabela foi calculada nas aulas de matemática. Fourez $(1997$, p. 119) diz que esta etapa caracteriza uma síntese parcial e objetiva da ilha de racionalidade produzida.

Etapa 7 - Abrir algumas caixas pretas sem a ajuda de especialista: Nas aulas de matemática pesquisamos na internet informações como: porção e peso líquido. As seguintes questões foram oriundas dos registros da etapa 1: a) Por que na bolacha tem peso líquido se é um alimento e não uma bebida? b) Por que na caixa dos cereais mostram as porções que dá naquela caixa? Já que em casa muitas vezes dá menos ou mais porções, depende da nossa fome.

Etapa 8 - Elaborar uma síntese da llha de Racionalidade produzida: Na etapa final produzimos um bolo de caneca e elaboramos os rótulos com imagem, tabela nutricional, validade, fabricação, ingredientes, entre outras informações, conforme figura 4.

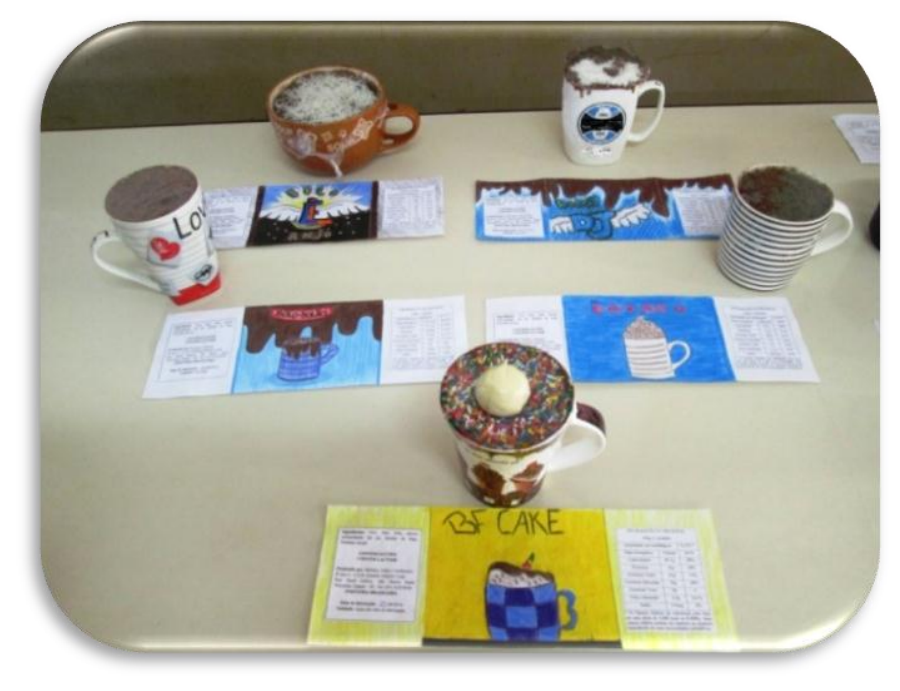

Figura 4 - Produto final. Produção de um bolo de caneca com rótulo.

(Fonte: acervo pessoal da pesquisadora)

Schmitz (2004, p. 119) afirma que: “Esta representação é interdisciplinar quando mantiver o traço que os diferentes especialistas ou especialidades - implicando na negociação compromissada - trouxeram à representação adotada". Para a produção do produto final foi necessário buscar conhecimentos em todas as áreas que estudamos.

\section{Considerações finais}

A metodologia de ensino Ilhas Interdisciplinares de Racionalidade constituiu-se como importante ferramenta aos professores para acompanhar de forma sistêmica todo o percurso do 
projeto. Em cada etapa percorrida vivenciamos o aprofundamento de questões relacionadas a compreensão de informações contidas em rótulos de alimentos. Questões estas, que além de envolver os conhecimentos prévios dos estudantes e seus familiares, também foram aprofundadas com todo o rigor da disciplina científica. O desenvolvimento do projeto oportunizou aprender conteúdos conceituais importantes de forma contextualizada, como a proporcionalidade.

Uma das contribuições da IIR que podemos apontar é a segurança que ela proporciona aos envolvidos no projeto, especialmente aos professores. A metodologia direciona o projeto interdisciplinar de modo que sentimos confiança no processo, impossibilitando o mesmo de se tornar algo simplório. Nos estudantes, percebemos que a metodologia provocou um sentimento de "sentir-se parte", pois a todo instante, eles eram desafiados por suas próprias caixas pretas. Além disso, se sentiram importantes participando das rodas de conversa com os especialistas. 0 vocabulário de todos os envolvidos foi enaltecido, a cada etapa a verbalização entre o grupo se tornava mais científica.

Ao final do projeto evidenciamos os objetivos da Alfabetização Científica, os estudantes possuíam domínio e capacidade para se comunicar a respeito das informações contidas em rótulos de alimentos, e autonomia para comparar alimentos e interpretar suas informações.

\section{Referências}

BETTANIN, E. As ilhas de racionalidade na promoção dos objetivos da alfabetização científica e técnica. Dissertação (Mestrado em Educação). UFSC. Florianópolis, 2003. 160 p.

BRASIL. Secretaria de Educação Fundamental. Parâmetros Curriculares Nacionais: terceiro e quarto ciclos do ensino fundamental - Matemática. Brasília: MEC/SEF, 1998a.

- Secretaria de Educação Fundamental. Parâmetros curriculares nacionais: terceiro e quarto ciclos: apresentação dos temas transversais. Brasília : MEC/SEF, 1998b.

FOUREZ, G. Alfabetización científica y tecnológica. Acerca de las finalidades de la enseñanza de las ciencias. Buenos Aires, Argentina: Ediciones Colihue, 1997.

G. Crise no Ensino de Ciências? Revista Investigações em Ensino de Ciências. Porto Alegre, v. 8, n. 2, p.109 -123, ago. 2003.

LUCCHESI, I. L. A ilha de racionalidade e a construção da autonomia no ensino de matemática. Dissertação (Mestrado em Educação em Ciências e Matemática ). PUCRS. Porto Alegre, 2010. $130 \mathrm{p}$.

MAINGAIN, A.; DUFOUR, B. Abordagens didácticas da interdisciplinaridade. Lisboa: Instituto Piaget, 2008.

174 DOI: Em andamento.

R. Bras. de Ensino de C\&T 
OLIVEIRA, L. M. C. P. Aprendizagens no empreendimento estudo do raciocínio proporcional. Dissertação (Mestrado em Ensino de Ciências e Educação Matemática). UEL. Londrina, 2014. 202p.

PIETROCOLA, M. et al. As ilhas de racionalidade e o saber significativo: o ensino de ciências através de projetos. Revista ENSAIO - Pesquisa em educação em ciências. Belo Horizonte, v. 2, n. 1, p. 99-122, mar. 2000.

PINHEIRO, T. F.; PINHO ALVES J. Ilhas de Racionalidade: experiências interdisciplinares na segunda série do ensino médio. IV Encontro Ibero-Americano de coletivos escolares e redes de professores que fazem investigação na sua escola. Lageado, RS. 2005.

SCHMITZ, C. Desafio docente: as ilhas de racionalidade e seus elementos interdisciplinares. Dissertação (Mestrado em Educação Científica e Tecnológica). UFSC. Florianópolis, 2004. 277 p.

TINOCO, L. A. A. Razões e proporções. Rio de Janeiro: UFRJ/IM, 2011.

Josiane Bernz Siqueira - Mestranda em Ensino de Ciências Naturais e Matemática - FURB PPGECIM. Universidade Regional de Blumenau - FURB. Professora de matemática da rede municipal de Gaspar e da rede estadual de Santa Catarina. Professora supervisora do Programa Institucional de Bolsas de Iniciação à Docência - PIBID/Matemática da Universidade Regional de Blumenau - FURB. professoramat_josiane@hotmail.com

Rosinéte Gaertner - Doutora em Educação Matemática - UNESP - Universidade Estadual Paulista Júlio de Mesquita Filho. Professora Voluntária do Programa de Pós Graduação em Ensino de Ciências Naturais e Matemática - PPGECIM - da Universidade Regional de Blumenau - FURB. rogaertner@gmail.com

DOI: Em andamento. 